\title{
THE INFLUENCE OF PRICE AND SERVICE QUALITY OF BRAND IMAGE AND ITS IMPACT ON CUSTOMER SATISFACTION GOJEK (STUDENTS STUDY ON A STATE UNIVERSITY OF JAKARTA)
}

\author{
Mohamad Rizan \\ Fakultas Ekonomi Universitas Negeri Jakarta \\ email: mohamadrizan72@gmail.com \\ Dahliana Yulianti \\ Fakultas Ekonomi Universitas Negeri Jakarta \\ email: dahlianayuliantimalau@gmail.com \\ Rahmi \\ Fakultas Ekonomi Universitas Negeri Jakarta \\ email: rahmi.unj@gmail.com
}

\begin{abstract}
The purpose of the research are to: test empirically influence of price to brand image on customer satisfaction Gojek, test empirically influence of service quality to brand image on customer satisfaction Gojek, test empirically influence of price on customer satisfaction Gojek, test empirically influence of service quality on customer satisfaction Gojek, test empirically influence of brand image on customer satisfaction Gojek. This study used confirmatory factor analysis. The research was conducted in State University of Jakarta and used purposive sampling techniques, while the data collecting technique used questionaire, SPSS and SEM LISREL for data processing. The result shows a significant influence of price and service quality for brand image and its impact on customer satisfaction.
\end{abstract}

Keywords: price, service quality, brand image, customer satisfaction 


\section{PENDAHULUAN}

\section{Latar Belakang Masalah}

Berkembangnya kebutuhan yang kian beragam menuntut tersedianya sarana dan prasarana yang baik. Transportasi merupakan unsur yang sangat berpengaruh dalam roda perekonomian. Dari tiga jenis transportasi, transportasi darat merupakan moda transportasi yang paling dominan dibandingkan moda transportasi udara dan transportasi laut di Indonesia. Besarnya peranan transportasi bagi kehidupan manusia menyebabkan bisnis di bidang jasa transportasi semakin meningkat.

Tabel 1. Market Size Transportasi

\begin{tabular}{ccc}
\hline Tahun & Rupiah (dalam triliun) & Pertumbuhan (\%) \\
\hline 2014 & 1.810 & 13,2 \\
\hline 2015 & 2.086 & 15,2 \\
\hline 2016 & 2.399 & 15 \\
\hline 2019 & 3.680 & 15,2 \\
\hline
\end{tabular}

Sumber: http://duniaindustri.com (2016)

Data dan Outlook Transportasi, Logistik dan Infrastruktur pada tahun 2009-2019 menyatakan bahwa market size sektor transportasi di Indonesia sangat signifikan. Peningkatan jumlah kendaraan yang cukup besar khususnya pada sepeda motor dikarenakan sepeda motor merupakan kendaraan yang ekonomis. Jasa transportasi darat seperti ojek dapat menjadi solusi yang efektif bagi masyarakat dalam mengatasi masalah kemacetan.

Gojek adalah perusahaan berbasis teknologi aplikasi yang menawarkan kemudahan reservasi angkutan ojek melalui aplikasi mobile. Gojek menjadi solusi utama dalam pengiriman barang, pesan antar makanan, berbelanja dan bepergian di tengah kemacetan kota Jakarta. Bukan hanya diterima oleh masyarakat, kehadiran ojek online mampu menggulirkan roda perekonomian bagi para pengemudinya sehingga potensi bisnis ojek online perlu diperhitungkan. 
Saat ini Gojek mengacu dengan aturan harga pada jam sibuk dan harga di luar jam sibuk yang telah ditetapkan. Gojek masih menempatkan harga sebagai strategi andalan untuk bersaing dengan kompetitornya. Harga untuk setiap layanan Gojek dinilai cukup kompetitif dan mampu bersaing di pasar sasaran mengingat cakupan Gojek yang begitu luas.

Layanan yang ditawarkan Gojek pun membuat diferensiasi tersendiri bagi pelanggan dan kompetitornya. Slogan Gojek “An ojek for every need” tampaknya memang terwakili dengan jenis layanan yang ditawarkan Gojek yaitu Go Food, Go Mart, Go Glam, Go Clean, Go Massage, Go Ride, Go Car dan Go Send. Banyaknya variasi layanan yang ditawarkan Gojek memberikan kemudahan kepada pelanggan dalam mengakses kebutuhan yang diinginkan.

Ojek yang merupakan moda transportasi konvensional yang sudah lama di Indonesia kini berubah menjadi sebuah institusi. Tentunya setelah ada nama Gojek, harus diikuti perkembangan seperti kemudahan, kenyamanan dan keamanan yang menjadi identitas Gojek. Terlepas dari konten Gojek yang menjadi pro dan kontra, paling tidak nama Gojek akan dilihat dan didengar semua orang kemudian masyarakat akan mencari tahu sendiri mengenai Gojek.

Dengan terpilihnya aplikasi Gojek sebagai aplikasi terbaik tahun 2015 mengindikasikan bahwa banyak masyarakat yang mengunduh dan memberikan rating yang baik terhadap aplikasi Gojek. Gojek juga meraih penghargaan dalam Indonesia Cellular Show (ICS) Award 2015 dengan kategori Best Mobile Apps. Menjadi kepuasan tersendiri bagi masyarakat Indonesia yang menggunakan aplikasi Gojek karena hal ini menunjukkan bahwa Gojek mulai diminati dan mendapat tempat di Indonesia.

\section{Identifikasi Masalah}

1. Masyarakat menginginkan jasa transportasi yang efektif dan efisien.

2. Banyaknya kompetitor dalam bidang transportasi ojek online.

3. Bertambahnya jumlah kendaraan yang memicu terjadinya kemacetan.

4. Penentuan harga berdasarkan jarak tempuh dan jenis layanan yang diinginkan sehingga harga tidak dapat ditentukan secara sepihak. 
5. Paradigma masyakarat mengenai ojek online memerlukan citra merek yang kuat.

6. Penggunaan jasa Gojek pada kalangan tertentu yang menggunakan smartphone dan memiliki aplikasi Gojek berdampak pada kepuasan pelanggan.

\section{Perumusan Masalah}

1. Bagaimana deskripsi dari harga dan kualitas pelayanan terhadap citra merek serta dampaknya pada kepuasan pelanggan Gojek?

2. Apakah harga berpengaruh positif terhadap citra merek pada kepuasan pelanggan Gojek?

3. Apakah kualitas pelayanan berpengaruh positif terhadap citra merek pada kepuasan pelanggan Gojek?

4. Apakah harga berpengaruh positif pada kepuasan pelanggan Gojek?

5. Apakah kualitas pelayanan berpengaruh positif pada kepuasan pelanggan Gojek?

6. Apakah citra merek berpengaruh positif pada kepuasan pelanggan Gojek?

\section{Tujuan Penelitian}

1. Untuk mengetahui deskripsi harga dan kualitas pelayanan terhadap citra merek serta dampaknya pada kepuasan pelanggan Gojek.

2. Untuk menguji secara empiris pengaruh harga terhadap citra merek pada kepuasan pelanggan Gojek.

3. Untuk menguji secara empiris pengaruh kualitas pelayanan terhadap citra merek pada kepuasan pelanggan Gojek.

4. Untuk menguji secara empiris pengaruh harga pada kepuasan pelanggan Gojek.

5. Untuk menguji secara empiris pengaruh kualitas pelayanan pada kepuasan pelanggan Gojek.

6. Untuk menguji secara empiris pengaruh citra merek pada kepuasan pelanggan Gojek. 


\section{KAJIAN TEORI}

\section{Deskripsi Konseptual}

\section{Kepuasan Pelanggan}

Menurut Tjiptono dan Chandra (Tjiptono dan Chandra, 2007: 292) kepuasan pelanggan adalah perasaan menyenangkan yang dimiliki saat mendapatkan sesuatu atau ketika sesuatu yang diinginkan terjadi. Kepuasan pelanggan dipengaruhi oleh persepsi nilai yaitu evaluasi menyeluruh dari kegunaan suatu jasa yang didasari oleh persepsi pelanggan terhadap manfaat yang diterima dibandingkan dengan pengorbanan yang dilakukan.

Menurut Schiffman dan Kanuk (Schiffman dan Kanuk, 2007: 9) kepuasan pelanggan adalah persepsi individu terhadap performa produk atau jasa yang berhubungan dengan ekspektasi pelanggan.

Menurut Kotler dan Armstrong (Kotler dan Armstrong, 2012: 13) kepuasan pelanggan adalah tingkat pencapaian performa dari sebuah produk atau jasa yang diterima oleh pelanggan sama dengan ekspektasi pelanggan itu sendiri.

Dari pemaparan para ahli dapat disimpulkan bahwa dimensi dari kepuasan pelanggan adalah kualitas pelayanan, harga, kemudahan yang diberikan dan faktor emosional antara penyedia jasa dengan pelanggan.

Menurut Tjiptono (Tjiptono dan Chandra, 2007a) kepuasan pelanggan terdiri dari lima dimensi yaitu:

1. Harga, pelanggan yang sensitif terhadap harga murah adalah sumber kepuasan yang penting karena pelanggan mendapatkan value of money yang tinggi.

2. Kualitas produk atau jasa, pelanggan merasa puas setelah membeli atau menggunakan produk atau jasa.

3. Kualitas pelayanan, kemampuan karyawan dalam memberikan pelayanan dengan baik.

4. Faktor emosional, kepuasan pelanggan timbul apabila mengonsumsi produk atau jasa yang disebabkan karena merek produk atau jasa sudah tercipta dengan baik dari segi harga dan kualitas. 
5. Kemudahan, pelanggan akan puas apabila merasa mudah, nyaman dan efisien dalam mendapatkan produk atau pelayanannya.

\section{Citra Merek}

Menurut Keller (Keller, 2008: 636) citra merek adalah persepsi pelanggan dan preferensi untuk merek yang diukur oleh berbagai jenis asosiasi merek yang ada dalam memori.

Menurut Supranto dalam Fadli (Fadli et al., 2013: 124) citra merek adalah apa yang pelanggan pikir atau rasakan ketika melihat atau mendengar nama suatu merek.

Menurut Ferranadewi (Ferranadewi, 2008: 165) citra merek merupakan konsep yang diciptakan oleh pelanggan karena alasan subyektif dan emosi pribadi.

Dari definisi di atas dapat disimpulkan bahwa citra merek merupakan elemen yang berkontribusi terhadap kesuksesan sebuah organisasi pemasaran baik perusahaan bisnis maupun nirlaba, pemanufakturan maupun penyedia jasa dan organisasi lokal maupun global.

Kapferer dalam Fadli (Fadli et al., 2013a) menyatakan enam dimensi citra merek adalah:

1. Fisik, yaitu penampilan merek dalam hal nama, warna dan logo kemasan yang dipilih.

2. Refleksi, yaitu citra pelanggan seperti komunikasi merek.

3. Keterkaitan, mengacu pada cara merek mencari hubungan dengan pelanggan.

4. Kepribadian, yang dimaksud adalah kepribadian merek.

5. Budaya, yaitu latar belakang dan nilai-nilai merek.

6. Citra diri, cara pelanggan melihat dirinya sendiri yang berhubungan dengan merek. 


\section{Harga}

Menurut Stanton (Stanton, 2007: 22) harga adalah sejumlah uang yang dibutuhkan untuk memperoleh beberapa kombinasi sebuah produk dan pelayanan yang menyertainya.

Menurut Hawkins dan Mothersbaugh (Hawkins dan Mothersbaugh, 2010: 21) harga merupakan sejumlah uang yang dibayarkan untuk mendapatkan hak memiliki atau menggunakan sebuah produk atau jasa.

Menurut Kotler dan Armstrong (Kotler dan Armstrong, 2012a) harga merupakan kecenderungan pelanggan untuk memberi penilaian tentang kesesuaian manfaat produk atau jasa. Penilaian terhadap harga pada suatu manfaat produk atau jasa tergantung dari persepsi individu yang dilatarbelakangi oleh lingkungan dan kondisi individu itu sendiri.

Berdasarkan pengertian para ahli, dapat disimpulkan bahwa harga merupakan biaya yang dikeluarkan oleh pelanggan dalam pembelian suatu produk atau jasa.

Menurut Pepadri dan Sitinjak dalam Wibowo dan Karimah (Wibowo dan Karimah, 2012: 8) terdapat empat dimensi yang digunakan untuk mengukur harga suatu produk atau jasa yaitu:

1. Referensi harga.

2. Harga relatif lebih murah.

3. Kewajaran harga.

4. Kesesuaian pengorbanan dan harga sesuai dengan manfaat.

\section{Kualitas Pelayanan}

Menurut Kotler dan Amstrong (Kotler dan Amstrong, 2012b) kualitas pelayanan adalah kegiatan yang dapat ditawarkan oleh suatu pihak kepada pihak lain yang pada dasarnya tidak berwujud dan tidak mengakibatkan kepemilikan apapun.

Menurut Tjiptono (Tjiptono, 2007b) kualitas pelayanan merupakan pernyataan tentang sikap dan hubungan yang dihasilkan dari perbandingan antara harapan dengan hasil yang diperoleh. 
Menurut Parasuraman (Parasuraman, 2008: 148) kualitas pelayanan adalah tingkat perbedaan antara kenyataan dan harapan pelanggan atas layanan yang diterima.

Dari definisi para ahli dapat disimpulkan bahwa kualitas pelayanan merupakan segala bentuk aktivitas yang dilakukan perusahaan guna memenuhi harapan pelanggan. Pelayanan dalam hal ini berupa kemudahan, kecepatan dan kemampuan yang ditujukan melalui sikap dalam memberikan pelayanan demi kepuasan pelanggan.

Tjiptono dan Chandra (Tjiptono dan Chandra, 2007c) menyimpulkan lima dimensi kualitas pelayanan yaitu:

1. Berwujud (tangible)

Kemampuan suatu perusahaan dalam menunjukkan eksistensinya kepada pihak eksternal. Penampilan dan fisik perusahaan yang dapat diandalkan merupakan bukti nyata dari pelayanan yang diberikan.

2. Keandalan (reliability)

Kemampuan perusahaan dalam memberikan pelayanan sesuai dengan yang dijanjikan secara akurat dan terpercaya. Kinerja harus sesuai dengan harapan pelanggan seperti ketepatan waktu, sikap simpatik dan pelayanan yang sama tanpa kesalahan.

3. Daya tanggap (responsiveness)

Kebijakan untuk memberikan pelayanan yang cepat dan tepat kepada pelanggan melalui penyampaian informasi yang jelas. Keinginan para karyawan untuk memberikan jasa yang dibutuhkan oleh pelanggan.

4. Jaminan (assurance)

Pengetahuan, kesopansantunan dan kemampuan para karyawan dalam perusahaan untuk menumbuhkan rasa percaya pelanggan terhadap perusahaan.

5. Empati (emphaty)

Memberikan perhatian tulus kepada pelanggan dengan memahami keinginan pelanggan melalui komunikasi yang baik, perhatian pribadi dan kemudahan dalam melakukan komunikasi. 
Dari penjabaran tersebut maka dihasilkan model penelitian atas harga (X1) berpengaruh terhadap citra merek (Y), kualitas pelayanan (X2) berpengaruh terhadap citra merek (Y), harga (X1) berpengaruh terhadap kepuasan pelanggan (Z), kualitas pelayanan (X2) berpengaruh terhadap kepuasan pelanggan (Z) dan citra merek (Y) berpengaruh terhadap kepuasan pelanggan (Z).

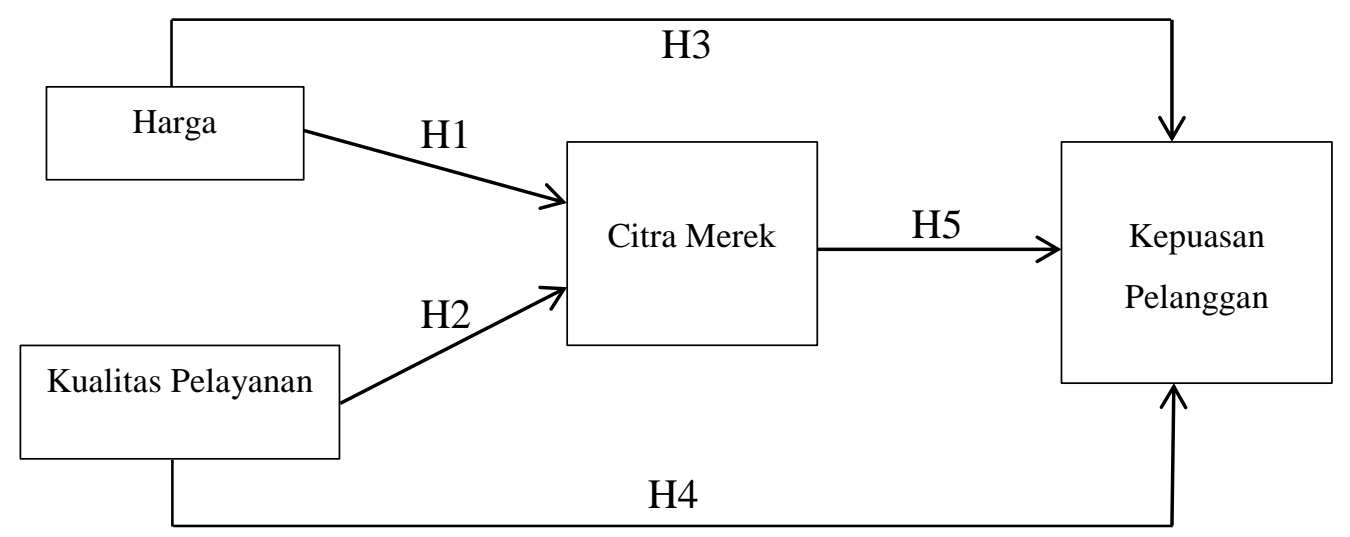

Gambar 1. Model Penelitian

Sumber: Data diolah peneliti (2016)

Berdasarkan kajian teori dan model penelitian maka dapat dirumuskan hipotesis penelitian sebagai berikut:

H1 : Harga berpengaruh positif terhadap citra merek.

H2 : Kualitas pelayanan berpengaruh positif terhadap citra merek.

H3 : Harga berpengaruh positif terhadap kepuasan pelanggan.

H4 : Kualitas pelayanan berpengaruh positif terhadap kepuasan pelanggan.

H5 : Citra merek berpengaruh positif terhadap kepuasan pelanggan.

\section{METODE PENELITIAN}

Metode penelitian yang digunakan adalah penelitian kuantitatif. Menurut Sugiyono (Sugiyono, 2012: 6) penelitian kuantitatif adalah penelitian yang bersifat deskriptif dan cenderung menggunakan analisis pendekatan induktif. Penelitian kuantitatif menitikberatkan pada pengukuran dan analisis hubungan sebab akibat setiap variabel. 
Desain penelitian adalah explanatory dengan jenis penelitian deskriptif dan kausal, yaitu peneliti akan melakukan pengujian terhadap hipotesis dan menguji pengaruh variabel independen terhadap variabel dependen yaitu harga, kualitas pelayanan, citra merek dan kepuasan pelanggan.

Metode pengumpulan data menggunakan metode survei melalui penyebaran kuesioner terstruktur yang diberikan kepada responden dan dirancang untuk mendapatkan informasi yang lebih spesifik.

\section{Populasi dan Sampling}

Menurut Sugiyono (Sugiyono, 2012a) populasi adalah wilayah generalisasi yang terdiri atas objek atau subjek yang mempunyai kualitas dan karakteristik tertentu yang ditetapkan oleh peneliti untuk dipelajari dan ditarik kesimpulannya. Penelitian ini memilih populasi melalui pelanggan yang pernah menggunakan alat transportasi Gojek.

Menurut Roscoe yang dikutip Uma Sekaran (Sekaran, 2007: 121) memberikan acuan umum dalam menentukan ukuran sampel salah satunya yaitu ukuran sampel lebih dari 30 dan kurang dari 500 adalah tepat untuk kebanyakan penelitian. Berdasarkan pada teori Roscoe, maka peneliti menetapkan jumlah sampel sebanyak 200 responden.

Metode sampling yang digunakan dalam penelitian ini adalah purposive sampling. Menurut Wiratna Sujarweni (Sujarweni, 2014: 71) purposive sampling adalah teknik penentuan sampel dengan pertimbangan dan kriteria tertentu.

Dalam hal ini responden yang memenuhi kriteria adalah pelanggan yang pernah menggunakan alat transportasi Gojek minimal dua kali. Dalam pengambilan sampel, peneliti akan menyebarkan kuesioner secara langsung kepada mahasiswa di Universitas Negeri Jakarta.

\section{Teknik Pengumpulan Data}

Penelitian ini menggunakan dua sumber data yaitu data primer dan data sekunder. Menurut Malhotra (Malhotra, 2009: 120) data primer adalah data yang 
dibuat oleh peneliti dengan tujuan menyelesaikan masalah riset. Data primer dalam penelitian ini diperoleh dari observasi, wawancara dan kuesioner.

Menurut Malhotra (Malhotra, 2009a) data sekunder adalah data yang dikumpulkan dengan tujuan tertentu selain menyelesaikan masalah riset. Data sekunder diperoleh dari jurnal yang berkaitan dengan masalah yang diteliti dan beberapa situs yang digunakan dalam pencarian referensi teori maupun jurnal.

Penelitian ini menggunakan skala Likert sebagai alat penelitian untuk mengukur pernyataan yang tercantum pada kuesioner. Menurut Malhotra (Malhotra, 2009b) skala Likert adalah skala pengukuran dengan lima kategori respon mulai dari sangat tidak setuju hingga sangat setuju yang mengharuskan responden untuk menentukan derajat terhadap serangkaian pernyataan mengenai objek stimulus.

\section{Teknik Analisis Data}

Penelitian ini menggunakan analisis data dengan SPSS versi 23 dan model SEM (Structural Equation Modelling) melalui software Lisrel versi 8.7.

\section{Uji Validitas}

Validitas merupakan indeks yang menunjukkan alat ukur mampu mengukur apa yang diukur. Kriteria yang digunakan dalam menentukan valid atau tidaknya instrumen dengan menggunakan bivariate pearson. Bivariate pearson merupakan analisis korelasi dengan mengkorelasikan masing-masing skor item dengan skor total, skor total merupakan penjumlahan dari keseluruhan item.

\section{Uji Reliabilitas}

Reliabilitas merupakan indeks yang menunjukkan alat ukur dapat dipercaya atau diandalkan. Uji reliabilitas menggunakan metode Cronbach Alpha dengan ukuran reliabilitas yaitu jika kurang dari 0,6 maka kurang baik, jika 0,7 maka dapat diterima dan jika 0,8 maka baik. 


\section{Uji Hipotesis}

Hasil uji hipotesis hubungan antar variabel ditunjukkan dari nilai standardized total effects yang merupakan hasil dari analisis data untuk mengetahui hubungan antar variabel. Nilai kritis untuk ukuran sampel besar (n > 30) dengan taraf $\alpha=0,05$ sebesar 1,96 .

\section{Uji Kesesuaian Model}

Indeks uji kesesuaian model pada SEM yaitu Chi-Square (CMIN) dengan cut-off value diharapkan kecil, Goodness of Fit Index (GFI) $\geq 0,90$, CMIN/DF $\leq$ 2,00, Tucker Lewis Index (TLI) $\geq 0,95$, Comparative Fit Index (CFI) $\geq 0,95$, Root Mean Square Error of Approximation (RMSEA) $\leq 0,08$.

\section{Uji Pengaruh Langsung dan Tidak Langsung}

Menurut Sanusi (Sanusi, 2011: 156) analisis jalur digunakan untuk menjelaskan akibat langsung dan tidak langsung seperangkat variabel bebas dengan seperangkat variabel terikat. Dalam analisis jalur, hubungan kausalitas yang menunjukkan pengaruh langsung dan tidak langsung antar variabel dapat diukur besarannya.

\section{HASIL DAN PEMBAHASAN}

\section{Deskripsi Data Variabel}

Pada variabel kepuasan pelanggan hasil evaluasi terhadap kepuasan pelanggan yang dilakukan Gojek sudah baik. Artinya pelayanan Gojek sesuai dengan harapan pelanggan sehingga pelanggan menilai Gojek secara positif. Hal ini menunjukkan bahwa pelanggan puas dalam menggunakan aplikasi layanan Gojek.

Pada variabel citra merek secara keseluruhan citra merek Gojek memiliki orientasi terhadap kepuasan pelanggan. Artinya merek Gojek yang terkenal dan mudah diingat masih direspon positif oleh pelanggan. Hal ini menunjukkan bahwa citra merek Gojek baik di benak pelanggan.

Pada variabel harga hasil perhitungan terhadap harga Gojek sudah baik namun masih ada pelanggan yang menilai negatif terkait harga yang diberikan 650 
Gojek. Hal itu disebabkan karena adanya persaingan antara ojek online sejenis sehingga memicu perkembangan harga pada Gojek.

Pada variabel kualitas pelayanan hasil penelitian menyatakan secara umum pelanggan dapat bersikap positif terhadap kualitas pelayanan Gojek. Hal ini menunjukkan bahwa Gojek memiliki kualitas pelayanan yang prima terhadap pelanggan.

\section{Uji Validitas dan Reliabilitas Data}

Hasil KMO variabel harga berdasarkan tabel menunjukkan KMO > 0,5 yaitu sebesar 0,928. Barlett's Test of Sphericity mempunyai signifikansi 0,00 yang telah memenuhi kriteria $<0,05$. Variabel harga memiliki nilai cronbach alpha sebesar 0,962. Berdasarkan hasil tersebut dinyatakan bahwa variabel harga adalah valid dan reliabel.

Hasil KMO variabel kualitas pelayanan berdasarkan tabel menunjukkan KMO > 0,5 yaitu sebesar 0,960. Barlett's Test of Sphericity mempunyai signifikansi 0,00 yang telah memenuhi kriteria $<0,05$. Variabel kualitas pelayanan memiliki nilai cronbach alpha sebesar 0,955. Berdasarkan hasil tersebut dinyatakan bahwa variabel kualitas pelayanan adalah valid dan reliabel.

Hasil KMO variabel citra merek berdasarkan tabel menunjukkan KMO > 0,5 yaitu sebesar 0,902. Barlett's Test of Sphericity mempunyai signifikansi 0,00 yang telah memenuhi kriteria $<0,05$. Variabel citra merek memiliki nilai cronbach alpha sebesar 0,933. Berdasarkan hasil tersebut dinyatakan bahwa variabel citra merek adalah valid dan reliabel.

Hasil KMO variabel kepuasan pelanggan berdasarkan tabel menunjukkan KMO > 0,5 yaitu sebesar 0,849. Barlett's Test of Sphericity mempunyai signifikansi 0,00 yang telah memenuhi kriteria $<0,05$. Variabel kepuasan pelanggan memiliki nilai cronbach alpha sebesar 0,906. Berdasarkan hasil tersebut dinyatakan bahwa variabel kepuasan pelanggan adalah valid dan reliabel. 
Second Order Construct

Tabel 2. Second Order Construct Variabel Harga

\begin{tabular}{cccc}
\hline Indeks & Cut Off Value & Hasil & Evaluasi Model \\
\hline RMSEA & $\leq 0.08$ & 0.043 & Fitted \\
\hline NFI & $\geq 0.90$ & 1.00 & Fitted \\
\hline NNFI & $\geq 0.90$ & 1.00 & Fitted \\
\hline CFI & $\geq 0.95$ & 1.00 & Fitted \\
\hline CMIN/DF & $\leq 2.00$ & 1.37 & Fitted \\
\hline RMR & $\leq 0.05$ & 0.0066 & Fitted
\end{tabular}

Hasil uji pada tahap ini menunjukkan bahwa model variabel harga menghasilkan tingkat penerimaan yang baik. Hal ini ditunjukkan dengan hasil dari uji kecocokan model (goodness of fit test) dengan seluruh kriteria yang dapat diterima pada rentang nilai yang diharapkan. Hasil dari pengujian variabel harga adalah RMSEA sebesar 0.043, NFI sebesar 1.00, NNFI sebesar 1.00, CFI sebesar 1.00, CMIN/DF sebesar 1.37 dan RMR sebesar 0.0066.

Tabel 3. Second Order Construct Variabel Kualitas Pelayanan

\begin{tabular}{cccc}
\hline Indeks & Cut Off Value & Hasil & Evaluasi Model \\
\hline RMSEA & $\leq 0.08$ & 0.065 & Fitted \\
\hline NFI & $\geq 0.90$ & 0.99 & Fitted \\
\hline NNFI & $\geq 0.90$ & 0.99 & Fitted \\
\hline CFI & $\geq 0.95$ & 0.99 & Fitted \\
\hline CMIN/DF & $\leq 2.00$ & 1.85 & Fitted \\
\hline RMR & $\leq 0.05$ & 0.023 & Fitted \\
\hline Sumber: Data diolah peneliti $(2016)$ & &
\end{tabular}

Hasil uji pada tahap ini menunjukkan bahwa model variabel kualitas pelayanan menghasilkan tingkat penerimaan yang baik. Hal ini ditunjukkan dengan hasil dari uji kecocokan model (goodness of fit test) dengan seluruh kriteria yang dapat diterima pada rentang nilai yang diharapkan. Hasil dari pengujian variabel kualitas pelayanan adalah RMSEA sebesar 0.065, NFI sebesar 0.99, NNFI sebesar 0.99, CFI sebesar 0.99, CMIN/DF sebesar 1.85 dan RMR sebesar 0.023 .

Tabel 4. Second Order Construct Variabel Citra Merek

\begin{tabular}{cccc}
\hline Indeks & Cut Off Value & Hasil & Evaluasi Model \\
\hline RMSEA & $\leq 0.08$ & 0.060 & Fitted \\
\hline NFI & $\geq 0.90$ & 0.99 & Fitted \\
\hline NNFI & $\geq 0.90$ & 0.99 & Fitted \\
\hline CFI & $\geq 0.95$ & 1.00 & Fitted \\
\hline CMIN/DF & $\leq 2.00$ & 1.72 & Fitted \\
\hline
\end{tabular}




\begin{tabular}{|c|c|c|c|}
\hline RMR & $\leq 0.05$ & 0.017 & Fitted \\
\hline
\end{tabular}

Hasil uji pada tahap ini menunjukkan bahwa model variabel citra merek menghasilkan tingkat penerimaan yang baik. Hal ini ditunjukkan dengan hasil dari uji kecocokan model (goodness of fit test) dengan seluruh kriteria yang dapat diterima pada rentang nilai yang diharapkan. Hasil dari pengujian variabel citra merek adalah RMSEA sebesar 0.060, NFI sebesar 0.99, NNFI sebesar 0.99, CFI sebesar 1.00, CMIN/DF sebesar 1.72 dan RMR sebesar 0.017 .

Tabel 5. Second Order Construct Variabel Kepuasan Pelanggan

\begin{tabular}{cccc}
\hline Indeks & Cut Off Value & Hasil & Evaluasi Model \\
\hline RMSEA & $\leq 0.08$ & 0.00 & Fitted \\
\hline NFI & $\geq 0.90$ & 1.00 & Fitted \\
\hline NNFI & $\geq 0.90$ & 1.01 & Fitted \\
\hline CFI & $\geq 0.95$ & 1.00 & Fitted \\
\hline CMIN/DF & $\leq 2.00$ & 0.44 & Fitted \\
\hline RMR & $\leq 0.05$ & 0.037 & Fitted \\
\hline Sumber: Data diolah peneliti $(2016)$ & &
\end{tabular}

Hasil uji pada tahap ini menunjukkan bahwa model variabel kepuasan pelanggan menghasilkan tingkat penerimaan yang baik. Hal ini ditunjukkan dengan hasil dari uji kecocokan model (goodness of fit test) dengan seluruh kriteria yang dapat diterima pada rentang nilai yang diharapkan. Hasil dari pengujian variabel kepuasan pelanggan adalah RMSEA sebesar 0.00, NFI sebesar 1.00, NNFI sebesar 1.01, CFI sebesar 1.00, CMIN/DF sebesar 0.44 dan RMR sebesar 0.037 .

Fit Model SEM

Tabel 6. Fit Model SEM

\begin{tabular}{cccc}
\hline Indeks & Cut Off Value & Hasil & Evaluasi Model \\
\hline RMSEA & $\leq 0.08$ & 0.042 & Fitted \\
\hline NFI & $\geq 0.90$ & 0.98 & Fitted \\
\hline NNFI & $\geq 0.90$ & 0.99 & Fitted \\
\hline CFI & $\geq 0.95$ & 1.00 & Fitted \\
\hline CMIN/DF & $\leq 2.00$ & 1.36 & Fitted \\
\hline RMR & $\leq 0.05$ & 0.028 & Fitted \\
\hline Sumber: Data diolah peneliti $(2016)$ & &
\end{tabular}

Sumber: Data diolah peneliti (2016) 
Fit Model SEM berguna untuk menyesuaikan kriteria indeks goodness of fit agar mendapatkan kesesuaian model yang baik. Nilai RMSEA sebesar 0.042, NFI sebesar 0.98, NNFI sebesar 0.99, CFI sebesar 1.00, CMIN/DF sebesar 1.36 dan RMR sebesar 0.028. Berdasarkan tabel, hasil yang ada sudah sesuai dengan kriteria indeks sehingga mengindikasikan bahwa model sudah fit dengan data yang ada.

\section{Pengaruh Langsung dan Tidak Langsung}

Tabel 7. Pengaruh Langsung dan Tidak Langsung

\begin{tabular}{clccc}
\hline $\begin{array}{c}\text { Variabel } \\
\text { Bebas }\end{array}$ & $\longrightarrow$ & $\begin{array}{l}\text { Variabel } \\
\text { Terikat }\end{array}$ & $\begin{array}{c}\text { Pengaruh } \\
\text { Langsung }\end{array}$ & $\begin{array}{c}\text { Pengaruh } \\
\text { Tidak } \\
\text { Langsung }\end{array}$ \\
\hline $\begin{array}{c}\text { Kualitas } \\
\text { Pelayanan }\end{array}$ & $\longrightarrow$ & Citra Merek & 0,277 & - \\
\hline Harga & $\longrightarrow$ & Citra Merek & 0,159 & - \\
\hline Citra Merek & $\longrightarrow$ & $\begin{array}{l}\text { Kepuasan } \\
\text { Pelanggan }\end{array}$ & 0,205 & - \\
\hline $\begin{array}{c}\text { Kualitas } \\
\text { Pelayanan }\end{array}$ & $\longrightarrow$ & $\begin{array}{l}\text { Kepuasan } \\
\text { Pelanggan }\end{array}$ & 0,210 & 0,238 \\
\hline Harga & $\longrightarrow$ & $\begin{array}{l}\text { Kepuasan } \\
\text { Pelanggan }\end{array}$ & 0,010 & 0,181 \\
\hline
\end{tabular}

Sumber: Data diolah peneliti (2016)

Berdasarkan hasil analisis data dapat dilihat pengaruh langsung variabel kualitas pelayanan terhadap citra merek sebesar 0,277, pengaruh langsung variabel harga terhadap citra merek sebesar 0,159, pengaruh variabel citra merek terhadap kepuasan pelanggan sebesar 0,205, pengaruh variabel kualitas pelayanan terhadap kepuasan pelanggan sebesar 0,210 dan pengaruh variabel harga terhadap kepuasan pelanggan sebesar 0,010 .

Pengaruh tidak langsung yang dimiliki variabel kualitas pelayanan terhadap kepuasan pelanggan sebesar 0,238 dan pengaruh tidak langsung variabel harga terhadap kepuasan pelanggan sebesar 0,181. Pengaruh tidak langsung terjadi karena adanya variabel intervening pada model penelitian diantara variabel harga dan variabel kualitas pelayanan dengan variabel kepuasan pelanggan. 


\section{Pengujian Hipotesis}

Tabel 8. Model Persamaan Struktural

\begin{tabular}{|c|c|c|c|c|c|c|}
\hline Hipotesis & $\begin{array}{c}\text { Variabel } \\
\text { Bebas } \\
\end{array}$ & $\longrightarrow$ & $\begin{array}{l}\text { Variabel } \\
\text { Terikat } \\
\end{array}$ & t-value & $\begin{array}{c}\text { Standardized } \\
\text { Total Effects }\end{array}$ & Interpretas \\
\hline H1 & Harga & & $\begin{array}{c}\text { Citra } \\
\text { Merek }\end{array}$ & 4.64 & 0,159 & Diterima \\
\hline $\mathrm{H} 2$ & $\begin{array}{l}\text { Kualitas } \\
\text { Pelayanan }\end{array}$ & & $\begin{array}{c}\text { Citra } \\
\text { Merek }\end{array}$ & 5.89 & 0,277 & Diterima \\
\hline H3 & Harga & & $\begin{array}{l}\text { Kepuasan } \\
\text { Pelanggan }\end{array}$ & 1.40 & 0,191 & Ditolak \\
\hline $\mathrm{H} 4$ & $\begin{array}{c}\text { Kualitas } \\
\text { Pelayanan }\end{array}$ & & $\begin{array}{l}\text { Kepuasan } \\
\text { Pelanggan }\end{array}$ & 5.43 & 0,448 & Diterima \\
\hline H5 & $\begin{array}{l}\text { Citra } \\
\text { Merek }\end{array}$ & $\longrightarrow$ & $\begin{array}{l}\text { Kepuasan } \\
\text { Pelanggan }\end{array}$ & 4.82 & 0,205 & Diterima \\
\hline
\end{tabular}

Sumber: Data diolah peneliti (2016)

Model persamaan struktural dibutuhkan untuk menguji data apakah hipotesis yang dibuat diterima atau tidak apabila $t$-value pada hasil persamaan struktural lebih besar dari 1.96 maka terdapat pengaruh yang signifikan antar variabel dan hipotesis dapat diterima tetapi jika nilai $t$-value lebih kecil dari 1.96 maka pengaruh antar variabel tidak signifikan dan hipotesis ditolak. Berdasarkan hasil model persamaan struktural dapat disimpulkan bahwa hubungan antar variabel memiliki nilai $t$-value lebih besar dari 1.96 artinya pengaruh antar variabel terbukti signifikan.

\section{KESIMPULAN DAN SARAN}

\section{Kesimpulan}

1. Hipotesis pertama menyatakan bahwa harga berpengaruh positif dan signifikan terhadap citra merek pengguna aplikasi layanan Gojek di Universitas Negeri Jakarta diterima.

2. Hipotesis kedua menyatakan bahwa kualitas pelayanan berpengaruh positif dan signifikan terhadap citra merek pengguna aplikasi layanan Gojek di Universitas Negeri Jakarta diterima.

3. Hipotesis ketiga menyatakan bahwa harga berpengaruh positif dan signifikan terhadap kepuasan pelanggan pengguna aplikasi layanan Gojek di Universitas Negeri Jakarta ditolak. 
4. Hipotesis keempat menyatakan bahwa kualitas pelayanan berpengaruh positif dan signifikan terhadap kepuasan pelanggan pengguna aplikasi layanan Gojek di Universitas Negeri Jakarta diterima.

5. Hipotesis kelima menyatakan bahwa citra merek berpengaruh positif dan signifikan terhadap kepuasan pelanggan pengguna aplikasi layanan Gojek di Universitas Negeri Jakarta diterima.

\section{Saran}

\section{Saran Akademik}

1. Penelitian ini dapat dilakukan kembali dan digeneralisasikan dengan objek penelitian yang berbeda seperti bus, kereta api, pesawat terbang dan angkutan umum lainnya yang sejenis.

2. Diharapkan pada penelitian selanjutnya menggunakan jumlah sampel yang lebih banyak dan luas seperti anak sekolah dan orang yang sudah bekerja serta menambahkan referensi review penelitian relevan sejenis yang lebih banyak agar hasil penelitian lebih akurat sehingga dapat diterapkan pada Gojek maupun secara general.

3. Dalam penelitian mendatang dapat dilakukan penambahan variabel penelitian seperti penambahan variabel promosi, loyalitas pelanggan dan niat perilaku pelanggan.

\section{Saran Operasional}

1. Diharapkan harga Gojek tidak terlalu tinggi dibandingkan dengan harga pesaing maka dari itu kebijakan penetapan harga perlu diperhitungkan secara matang.

2. Diharapkan layanan yang diberikan oleh Gojek kepada pelanggan sesuai dengan prosedur yang dibutuhkan pelanggan dan Gojek dapat melakukan pembaharuan sistem aplikasi yang berkelanjutan.

3. Gojek harus mampu bersaing dengan kompetitor yang sejenis dengan mengedepankan kualitas yang baik. Persepsi pelanggan penting untuk keberlangsungan perusahaan karena itu citra harus dijaga dan ditingkatkan. 
4. Gojek dituntut untuk bersikap profesional dengan memperhatikan masukan pelanggan, meningkatkan mutu sistem agar Gojek mudah didapat, tidak menolak penumpang serta jujur dan ikhlas dalam melayani pelanggan.

Gojek harus memperbaiki performanya agar pelanggan tidak beralih ke kompetitor lain dengan cara memberikan promo atau diskon kepada pelanggan melalui kerjasama dengan bank tertentu atau mendapatkan poin reward untuk setiap penggunaan jasa Gojek.

\section{DAFTAR RUJUKAN}

Ahmad, S. 2011. Metode Penelitian Bisnis. Jakarta: Salemba Empat.

Fadli, U., Eman Sulaeman dan Heny Noor Padilah. 2013. Pengaruh Brand Image Terhadap Loyalitas Pelanggan Pada Farina Beauty Clinic. Jurnal Manajemen, p.124.

Ferrinadewi, E. 2008. Merek dan Psikologi Konsumen, Implikasi pada Strategi Pemasaran. Yogyakarta: Graha Ilmu.

Hawkins, D.I., dan Mothersbaugh D.L. 2010. Consumer Behaviour:Building Marketing Strategy. New York: McGraw-Hill.

Keller, L. 2008. Strategic Brand Management. New Jersey: Pearson Pretince Hall.

Kotler, P., dan Garry Amstrong. 2012. Prinsip-Prinsip Pemasaran. Jakarta: Erlangga.

Malhotra, N.K. 2009. Riset Pemasaran. Jakarta: PT. Indeks.

Parasuraman. 2008. Delivering Quality Services Balancing Customer Perceptions and Expections. New York: The Free Press.

Schiffman, L.G., dan Lesley L. Kanuk. 2007. Consumer Behaviour. New Jersey: Pearson Pretince Hall.

Sekaran, U. 2007. Metode Penelitian Bisnis. Jakarta: Salemba Empat.

Stanton, W. 2007. Prinsip-Prinsip Pemasaran. Jakarta: Erlangga.

Sugiyono. 2007. Metode Penelitian Administrasi. Bandung: Alfabeta.

Sujarweni, W. 2014. Metodologi Penelitian. Yogyakarta: Pustaka Baru Press.

Suwismo, A. 2016. Data dan Outlook Transportasi Logistik dan Infrastruktur 
Jurnal Riset Manajemen Sains Indonesia (JRMSI) | Vol 6, No. 2, 2015

2009-2019. Diunduh dari internet http://duniaindustri.com pada tanggal 26 Januari 2016.

Tjiptono, F., dan Gregorius Candra. 2007. Service, Quality \& Satisfaction.

Yogyakarta: Andi Offset.

Wibowo, S.F., dan Karimah M.P. 2012. Pengaruh Iklan Televisi dan Harga terhadap Keputusan Pembelian Sabun Lux. Jurnal Riset Manajemen Sains

Indonesia, p.8. 